\title{
Nephrotic Syndrome with Lesion of Segmental Hyalinosis
}

National Cancer Institute

\section{Source}

National Cancer Institute. Nephrotic Syndrome with Lesion of Segmental Hyalinosis. NCI Thesaurus. Code C35534.

A renal functional disorder characterized by proteinuria, edema, hyperlipidemia and hypoalbuminemia. It results from damage to the renal vascular filtration apparatus. It is further characterized by an inflammatory reaction in the filtering capillaries and the deposition of plasma components between the endothelium and glomerular basement membrane. Sequelae may include hypertension, atherosclerosis, infection, hypercoagulablity and renal failure. 